\title{
Besondere Sitzung vom 28. November 1903.
}

Vorsitzender: Hr. C. Liebermann, Vicepräsident.

Der Vorsitzende begrüsst die von answärts erschienenen Mitglieder, sowie zahlreiche Nichtmitglieder aus technischen und militärischen Kreisen, welche das Interesse an dem auf der Tagesordnung stehenden Vortrag als Gäste in diese Sitzung der chemischen Gesellschaft geführt habe. Hrn. Prof. Dr. W. Will (Berlin) dankt er für die Bereitwilligkeit, wit der er dem Ersuchen des Vorstandes um diesen zusammenfassenden Vortrag gefolgt sei, und ertheilt ihm hierauf das Wort zu seinem Vortrage:

- Der Fortechritt der Sprengtechnik seit der Entwickelung der organischen Chemie.s

In einem kurzen Schlusswort, welches auch die Bedeutung der Chemie und Technologie der Sprengstoffe für zahlreiche hohe Culturaufgaben der Menschbeit hervorhebt, dankt der Vorsitzende namens der Versammlung wie der Deutscben chemischen Gesellschaft dem Vortragenden für seinen lehrreichen, formvollendeten und weit ausblickenden Vortrag, wie er nur Demjenigen möglich sei, der sein eigenstes Arbeitsgebiet in vollstem Maasse beherrscht. Der Beifall der Versammlung habe gezeigt, dass sie sich schon im Voraus diesem Danke des Vorsitzenden angeschlossen habe.
Der Vorsitzende:
Der Schriftführer:
C. Liebermann.
A. Pinner. 